\title{
Bacterial biofilms formed in arsenic-containing water: biodeterioration of water network materials
}

\author{
Silvia E. Rastelli, Blanca M. Rosales, Marisa R. Viera and Cecilia I. Elsner
}

\begin{abstract}
The immersion of any material in a water system triggers a surface microbial colonization which simultaneously influences the corrosion behavior of the substratum. The present study was focused on the $\mathrm{As}(\mathrm{V})$ influence on the biofilm formation and their consequences on the corrosion behavior of different substrata. Commercial materials used in water distribution networks: alloys based on Fe, Zn and $\mathrm{Cu}$ and polypropylene (as blank) were tested in laboratory water closed circuits either in the absence or presence of $5 \mathrm{mg} \mathrm{L}^{-1} \mathrm{As}(\mathrm{V})$. Microbial sessile counting, microscopic techniques (SEM, ESEM, CSLM), and anodic polarization curves were performed. All the materials revealed very different behaviors. Except for copper, bacterial counts were higher for those coupons exposed to the water with $\mathrm{As}(\mathrm{V})$. The morphology of the corrosion products as well as the development of the corrosion process were highly influenced by the characteristics of the microbial biofilm, the nature of the substrata, and the presence or not of $\mathrm{As}(\mathrm{V})$.

Key words | arsenic, biofilms, corrosion behavior, microbial influenced corrosion, water network materials

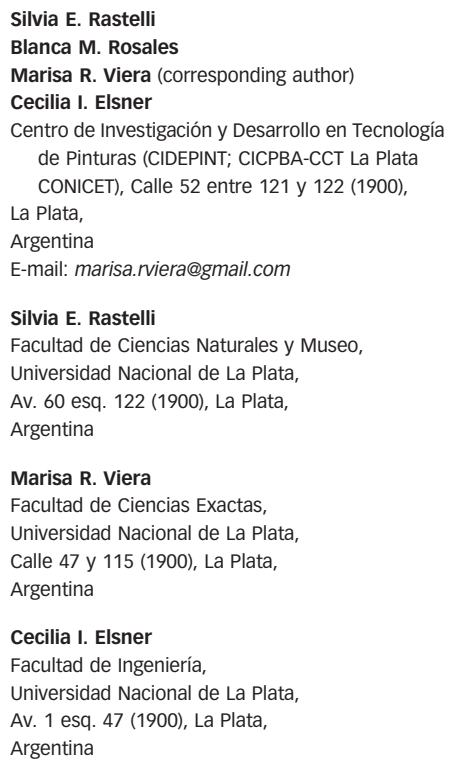

\section{INTRODUCTION}

The microbial colonization of any solid substratum induces biofilm development, which may be defined as a microbial derived sessile community characterized by cells attached on a substratum. The structure, chemistry, and physiology of the biofilms vary with the nature of the resident microbes and local environment. An important component for maintaining its structural integrity is a matrix of extracellular polymeric substances (EPS) (Beech et al. 2005; Branda et al. 2005). The pipe material, the presence of disinfectants, the water flow velocity, and many other variables influence their characteristics (Ollos et al. 2003; Lehtola et al. 2006).

In a water distribution system (WDS), the inner attack of pipelines is normally attributed to microbial influenced corrosion (MIC). In this condition, not only the presence of the biofilm but also the microbial activity within it can affect the kinetics of the electrochemical processes and consequently modify the characteristics of the corrosion products, leading doi: $10.2166 /$ aqua.2015.136 to either acceleration or inhibition of corrosion (Beech \& Sunner 2004). Due to this, the characterization of the biofilms formed on the metallic surface is of paramount importance in MIC studies. Electron microscopy techniques such as scanning electron microscopy (SEM) and environmental scanning electron microscopy (ESEM) have been very useful for high resolution visualization of bacterial biofilms. SEM observation requires the biofilm fixation, drying and conductively coating prior to imaging under high vacuum, which may alter its structure (Priester et al. 2007). On the other hand, ESEM observation requires moderate vacuum in a moisture-containing atmosphere and no coating, preserving the original morphology (Walker et al. 200I). Alternatively, confocal scanning laser microscopy (CSLM) in combination with different staining protocols is increasingly considered as an important tool allowing in situ analysis of the inner and outer structure, composition, 
compactness, processes, and dynamics of mixed environmental microbial communities usually encountered in the form of aggregates and biofilms (Pitts \& Stewart 2008; Neu et al. 20IO).

Another problem which is attracting great attention in the scientific community is the presence of chemical pollutants in water, either anthropogenic or of natural origin. Among them, arsenic (As) is being increasingly detected in WDS, generating serious sanitary and social problems in large urban areas throughout the planet (Frost et al. I993; Pontius et al. I994; Chatterjee et al. I995; Das et al. I995; Masud Karim 2000).

The current work is part of a large research project in which arsenic-tolerant bacterial communities present in water is of concern. They were characterized by classical and molecular microbial techniques and their influence on the corrosion behavior of water network materials was studied. This subject is of paramount interest in Argentina because in certain regions of the country groundwater attains high levels of arsenic, in the order of $0.6-4.8 \mathrm{mg} \mathrm{L}^{-1}$ (Farías et al. 2003; Pérez-Carrera \& Fernández-Cirelli 2007; Nicolli et al. 2012). In a preliminary study (Rosales et al. 2008), the biofilm development on commercial raw materials exposed to water in static conditions was analyzed and its effect on the corrosion behavior of those materials was evaluated. To be closer to the actual hydrodynamic condition in an urban water network, in this work, two experimental closed circuits with water circulation with or without As(V) were built up. In those conditions, the biofilm formation and its effect on the corrosion behavior of commercial raw materials commonly used in those networks was evaluated. The tests were designed to analyze in the greatest possible detail the many processes occurring during the initial steps (up to 45 days) of microbial colonization.

\section{MATERIALS AND METHODS}

\section{Materials and experimental arrangements}

Different materials commonly used in WDS were selected for this study: commercial iron (Fe) (instead of cast iron), zinc $(\mathrm{Zn})$ (instead of galvanized steel), copper alloy $(\mathrm{Cu})$
(Hidro-Bronz $^{\circledR}$ ), and polypropylene (PP). The materials and symbols used are shown in Table 1.

To perform the tests, two experimental closed circuits were built up (Figure 1(a)). Each circuit consisted of a 50 L PVC covered storage tank coupled with a rectangular $\mathrm{PP}$ pipeline (inner diameter $=2.32 \mathrm{~cm}$ ) of approximately $200 \mathrm{~cm}$ of overall length. In the lower horizontal part of the line, a transparent removable $20 \mathrm{~cm}$ acrylic cell was fixed. Near to the bottom of the transparent cell wall, seven coupons of $1 \mathrm{~cm} \times 1 \mathrm{~cm} \times 0.02 \mathrm{~cm}$ of each considered material were adhered to a curved polyethylene support in an arrangement like that shown in Figure 1(b).

As any irregularity in the inner tubing wall would strongly affect not only the biofilm deposition but also the attachment processes, to minimize flux perturbations as well as spurious solid material accumulation the test samples of the metallic materials were rolled and the PP ones thermocompressed up to $0.02 \mathrm{~cm}$ thickness. Prior to each test, all the metallic surfaces were uniformly grinded with water wet 1,000 emery paper. PP samples were tested 'as received' after thermocompression to avoid scratching during polishing.

The water circulation was afforded by a centrifugal pump at $79 \mathrm{~cm} \mathrm{~s}^{-1}$ (laminar flow). To simulate the flux of a domestic network in the laboratory arrangement, a water circulating program consisting of alternated 30/60 minutes work/stop periods during the day and no flow at night was applied.

To characterize the initial condition of the used water, its main chemical components, free residual chloride, and pH were determined. The results are shown in Table 2.

Before the beginning of each test series, both storage tanks were washed with ethylic alcohol and then rinsed several times with drinking water. To evaluate the influence of $\mathrm{As}(\mathrm{V})$ on the behavior of the system, one of the tanks was filled with the water supplemented with $\mathrm{Na}_{2} \mathrm{HAsO}_{4} \cdot 7 \mathrm{H}_{2} \mathrm{O}$ up to an $\mathrm{As}(\mathrm{V})$ concentration of $5 \mathrm{mg} \mathrm{L}^{-1}$. To render possible

\begin{tabular}{lll} 
Table $\mathbf{1}$ | Sample materials and used symbols & \\
Symbol & Material & Characteristic \\
\hline $\mathrm{Fe}$ & Low carbon steel & AISI 1005 steel \\
$\mathrm{Zn}$ & Commercial zinc & $\mathrm{Zn} 98 \%, \mathrm{Cu} 1 \%, \mathrm{Ti}+\mathrm{Mg} \mathrm{1 \%}$ \\
$\mathrm{Cu}$ & Copper alloy & Hidro-Bronz \\
& \\
$\mathrm{PP}$ & Polypropylene & $-\left(\mathrm{C}_{3} \mathrm{H}_{6}\right)-{ }_{n}$ \\
\hline
\end{tabular}


(a)

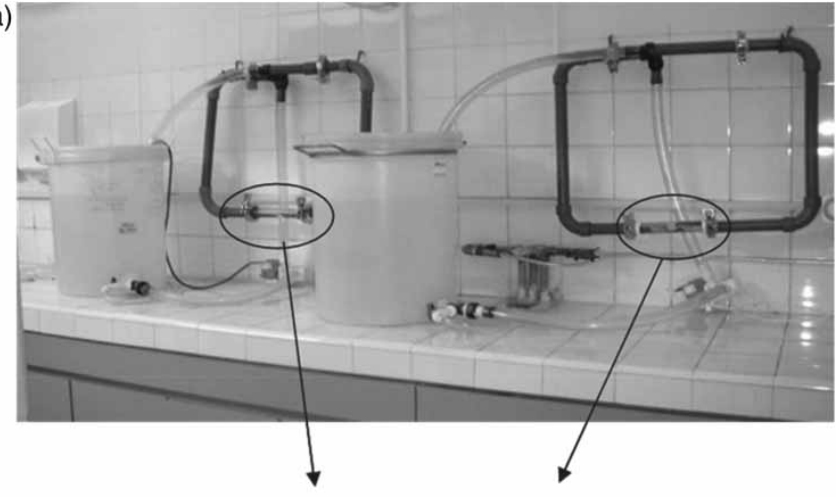

(b)

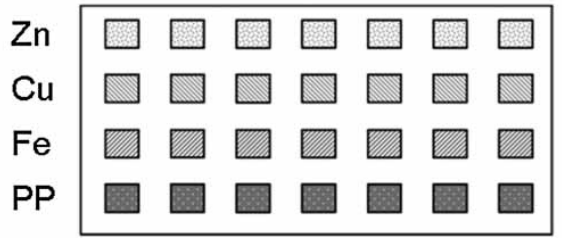

Figure 1 | (a) Experimental loops for dynamic tests; (b) arrangement of coupons within the removable cells (shown in circles in (a)).

Table 2 | Main physicochemical parameters of the water used in the experiments

\begin{tabular}{ll} 
Parameter & Value \\
\hline $\mathrm{pH}$ & 6.5 \\
Initial free $\mathrm{Cl}_{2}(\mathrm{mg} / \mathrm{L})$ & $0.5-0.6$ \\
$\mathrm{Ca}^{2+}(\mathrm{mg} / \mathrm{L})$ & 17 \\
$\mathrm{Mg}^{2+}(\mathrm{mg} / \mathrm{L})$ & 19 \\
$\mathrm{Na}^{+}(\mathrm{mg} / \mathrm{L})$ & 75 \\
$\mathrm{~K}^{+}(\mathrm{mg} / \mathrm{L})$ & 5 \\
$\mathrm{Cl}^{-}(\mathrm{mg} / \mathrm{L})$ & 130 \\
$\mathrm{SO}_{4}^{2-}(\mathrm{mg} / \mathrm{L})$ & 105
\end{tabular}

the statistical analyses, 10 test series were performed in both circuits. The exposition period was set at 45 days determined according to the amount of biofilm and spurious solids accumulated on the samples. Due to the amount of biofilm and spurious solids accumulated on the samples, the exposition period of each test series was set at 45 days.

\section{Sessile bacteria enumeration}

Once the exposure was finished, the samples were removed using aseptic techniques. Three coupons of each material were rinsed with sterile physiological solution $(0.9 \mathrm{~g} \mathrm{NaCl} / 100 \mathrm{~mL})$ to eliminate any planktonic bacteria from the surfaces. To collect the attached material (biofilm cells, EPS, and corrosion products) each coupon was scraped with a sterile scalpel and poured into $1 \mathrm{~mL}$ sterile physiological solution. After serial dilutions, $0.1 \mathrm{~mL}$ aliquots were seeded in nutrient agar (plurypeptone $5 \mathrm{gL}^{-1}$; beef extract $3 \mathrm{gL}^{-1} ; \mathrm{NaCl}$ $8 \mathrm{gL}^{-1}$; agar $15 \mathrm{gL}^{-1}$ ) and incubated during 72 hours at $25{ }^{\circ} \mathrm{C}$. The number of colony forming units was averaged to get the total sessile bacterial count on each material. The microbial counting performed was statistically analyzed by ANOVA two ways $(\alpha=0.05)$, followed by pair comparison tests with statistical software.

\section{Biological and inorganic film characterization}

Macroscopic aspect of the complex deposits was observed and photographed by an Arcano trinocular stereoscopic ANT WT 4130 with Moticam 10001.3 Mpixel USB 20 camera.

The surface analysis of one replicate of each considered material, before and after exposure, was accomplished using a Zeizz Supra ${ }^{\mathrm{TM}} 40$ SEM and a Philips XL 30 ESEM coupled to an energy-dispersive spectroscopy (EDS) analyzer for detailed aspect comparison observation and elemental analysis, respectively. 
SEM observations of biofilms were preceded by fixation with glutaraldehyde $2.5 \%$ in phosphate-buffered saline (PBS), dehydration with ethanol 20-100\%, critical point drying and surface-conductive ultra-thin coating on all samples.

To analyze the corrosion suffered by the exposure substrata, the deposits were removed following the standard ASTM G1-03 (20II): one coupon of each material was treated with $3 \% \mathrm{w} / \mathrm{v}$ hexamethylentetramine in $50 \% \mathrm{v} / \mathrm{v}$ hydrochloric acid in distilled water for 5 minutes, then they were rinsed with sterile distilled water and observed by SEM.

Biofilms' inner structure was observed and photographed by a CSLM (Olympus FV 300 with acquisition soft FLUOVIEW 3.5 version). Each image was taken at $100 \times$ on $5 \mu \mathrm{m}$ slices in the complete thickness along biofilms at $488 \mathrm{~nm}$ wave length. Cells were dyed with acridine orange reagent $0.01 \%$ in PBS. The 3-D images were reconstructed by freely available software ImageJ (http://rsb.info.nih.gov/ $\mathrm{ij} /)$.

After exposure, the corrosion products of one coupon of each material were analyzed by X-ray diffraction using a Philips 3020 with $\mathrm{PW}$ 3710, $\mathrm{Cu}-\mathrm{K} \alpha$ radiation, Ni filter, $40 \mathrm{kV}-20 \mathrm{~mA}$, without monochromator in the $2 \theta$ scanning range $5^{\circ}-70^{\circ}$.

\section{Electrochemical measurements}

To evaluate the influence of the film formation on the electrochemical behavior of the exposed materials, anodic polarization curves were performed. The electrochemical cell consisted of a three electrode arrangement with a cylindrical graphite bar $(4 \mathrm{~cm}$ length and $0.5 \mathrm{~cm}$ diameter) placed at the top of the cell as a counter electrode, and a saturated $\mathrm{Hg} / \mathrm{HgSO}_{4}$ electrode as reference (SSE). Samples of the tested materials, exposed or not, to the drinking water closed circuits were used as working electrodes. To avoid the damage of the less adherent material formed in the exposed samples, the working electrode was placed horizontally facing up, at the bottom of the cell. The electrical contact was attained with a copper wire fixed on the back of each coupon with a drop of tin. The contacts were isolated with an epoxy resin, leaving $1 \mathrm{~cm}^{2}$ of exposed area to the electrolyte.
The anodic polarization curves were performed in triplicate using an EG\&G Princeton Applied Research model 273A potentiostat/galvanostat in the potential range $-25 \mathrm{mV} \leq E_{\text {corr }} \leq 500 \mathrm{mV}$ at a scan rate of $0.166 \mathrm{mV} \mathrm{s}^{-1}$. All the measurements were performed in aerated $0.1 \mathrm{M}$ $\mathrm{Na}_{2} \mathrm{SO}_{4}$ solution at room temperature. Previous to the electrochemical measurements, non-exposed samples were mechanically abraded up to 1,000 grade grinding paper.

\section{RESULTS AND DISCUSSION}

\section{Sessile bacteria enumeration}

The total heterotrophic sessile bacterial number harvested depended on the analyzed substratum. The average of the sessile bacteria counting collected from each material at the end of 10 exposure series, in the presence and absence of $\mathrm{As}(\mathrm{V})$, is shown in Figure 2. This figure reveals not only differences among the average count obtained on the four tested materials but also an influence of the presence of the contaminant. Biofilms developed on Fe and $\mathrm{Zn}$ exhibited the highest counts, while biofilms on $\mathrm{Cu}$ and PP were one or two orders of magnitude lower. These results are in agreement with the observations made by other authors who found that the number of bacteria attached to iron or steel was higher than that on plastic or copper pipes (Yu et al. 20I0; Wang et al. 2012). Slightly higher values were found in biofilms developed in the As-containing circuit except in the case of $\mathrm{Cu}$. The statistical analysis of these data showed that the presence of arsenic exerted a significant effect on the biofilm development on $\mathrm{Zn}$ and $\mathrm{Cu}$. Biofilm formation allows microorganisms to survive in the presence of contaminants (Fang et al. 2002). In the present case, this hypothesis seems to be confirmed by the higher bacterial counts in those coupons exposed to arsenic-containing water, except in the case of $\mathrm{Cu}$. Furthermore, the low counts obtained on $\mathrm{Cu}$ in both systems could be related to the release of toxic copper ions ( $\mathrm{Yu}$ et al. 20Io).

\section{Biological and inorganic film characterization}

Since the beginning of water circulation, heterogeneously distributed microbial biofilms were formed on all the 


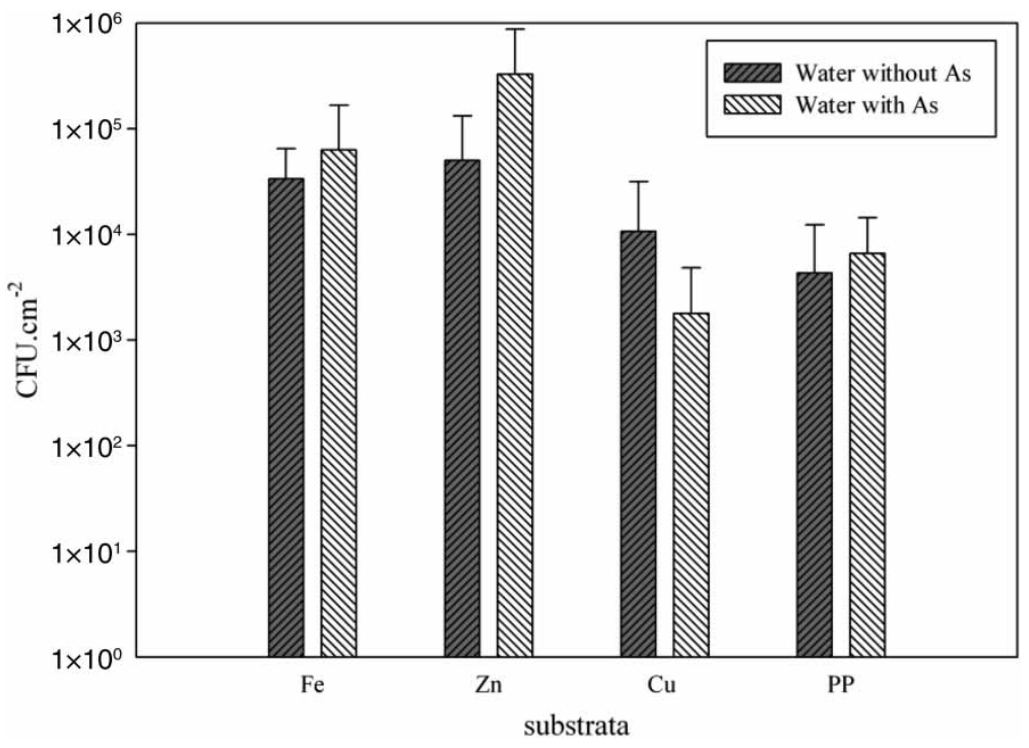

Figure 2 Average of total heterotrophic sessile bacteria counts on the assayed materials in water circuits in the absence and presence of As(V). The $\mathrm{CFU} . \mathrm{cm}^{-2}$ is represented in logarithmic scale.

exposed materials. As time went by, mixed up with the biological deposits, increasing amounts of corrosion products and spurious solids appeared on $\mathrm{Fe}, \mathrm{Zn}$, and $\mathrm{Cu}$ samples. At the end of exposure, the macroscopic final aspect of the complex film (microorganisms + EPS + corrosion products) deposited on the coupons was observed; in general, very scattered results were obtained among replicates of each material due to the uneven microbial colonization that could be appreciated even by the naked eye from outside the circuit during all the test series. In spite of that, it is possible to state that the amount of biological material and corrosion products was more significant on $\mathrm{Zn}$ and $\mathrm{Fe}$ than on $\mathrm{Cu}$ and PP.

Observations accomplished with different image analysis equipment on less colonized areas of the replicates of each material at a wide range of magnifications allowed the observation of the initial colonization stages (Figure 3). $\mathrm{Cu}$ and PP coupons did not show any appreciable feature at low magnification, while on $\mathrm{Zn}$ and $\mathrm{Fe}$, the most susceptible to colonization and corroded materials, superimposed layers of different morphology and thickness were observed (indicated with white arrows in the figure).

ESEM observations of the biofilms made at the end of exposure are shown in Figure 4. The complex nature of the films formed on $\mathrm{Fe}$ and $\mathrm{Zn}$ can be appreciated in the micrographs, where different corrosion products appeared mixed with bacterial cells. Results obtained by X-ray diffraction on $\mathrm{Fe}$ showed the presence of amorphous material; while on $\mathrm{Zn}$, metallic base $\left(\mathrm{Zn}^{\circ}\right)$, basic carbonate $\left(\mathrm{Zn}_{5}\left(\mathrm{CO}_{3}\right)_{2}(\mathrm{OH})_{6}\right)$ (hidrozincite), and $\mathrm{Zn}_{5}(\mathrm{OH})_{8} \mathrm{Cl}_{2} \cdot \mathrm{H}_{2} \mathrm{O}$ were detected in both circuits, and in the presence of arsenic water, $\mathrm{Zn}\left(\mathrm{AsO}_{2}\right)_{2}$ (zincmetaarsenite) was also identified.

On the $\mathrm{Cu}$ surface, spheroid structures, identified as $\mathrm{Cu}_{2} \mathrm{O}$ by X-ray diffraction were observed. On PP, a thin single phased biofilm can be observed. The lower thickness of the films formed on $\mathrm{Cu}$ and PP must be the cause allowing visualizing microbes in these biofilms. EDS analyses showed that the biological products deposited on PP are mixed with corrosion products coming from the nearby metallic samples. The X-ray spectrum revealed the presence of the organic phase polypropilene $\left(\mathrm{C}_{3} \mathrm{H}_{6}\right)_{n}$ and claudetite $\left(\mathrm{As}_{2} \mathrm{O}_{3}\right)$. The existence of $\mathrm{As}(\mathrm{III})$ on PP coupons is the result of the reduction of the $\mathrm{As}(\mathrm{V})$ added to the water. In the absence of any galvanic effect, its presence reveals the existence of at least one bacterial species able to use this element as an electron acceptor during anaerobic respiration (Oremland \& Stolz 2005). Several authors (Oremland et al. 2004; Oremland \& Stolz 2005) provided evidence that arsenic mobility in polluted waters could be associated with interaction with microbial biofilms of 

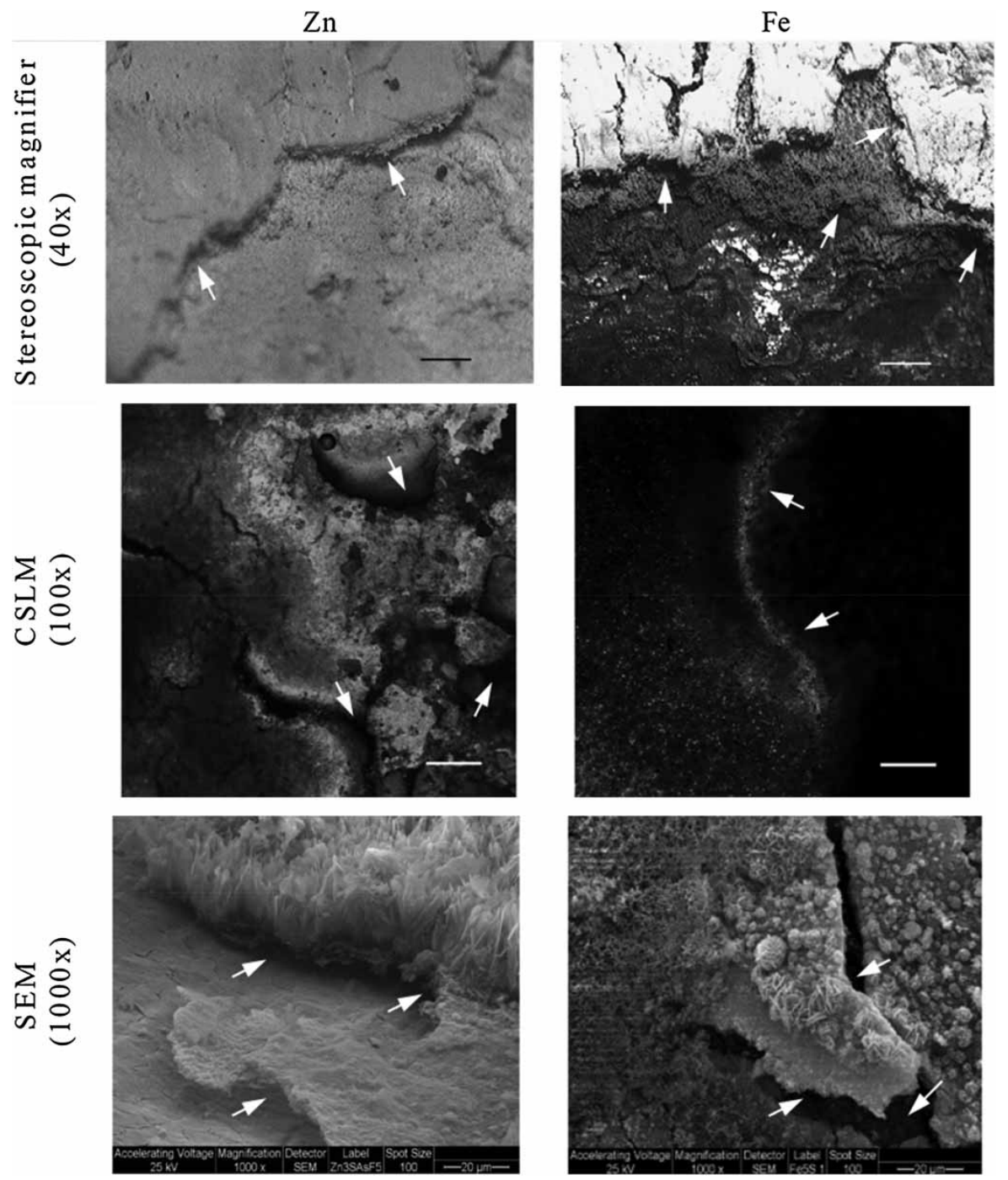

Figure 3 | Structural aspect of complex deposits on the most susceptible to colonization materials, Zn and Fe, with different image analysis equipment. Stereoscopic magnifier bar: $500 \mu \mathrm{m}$; CSLM bar: $200 \mu \mathrm{m}$; SEM bar: $20 \mu \mathrm{m}$. White arrows indicate different distinguishable layers.

diverse structure and suggested arsenic removal by bacterial species with that capability. For all the exposed materials, the EDS analysis detected the presence of As on the surface of the samples exposed to the As-containing water. Moreover, arsenic detection was only possible in areas where the biofilm was developed.

To evaluate the influence of the presence of arsenic in the circulating water on the final metallic surface aspect after 45 days of exposure, SEM micrographs were obtained after the removal of the deposits (inorganic + biological) (Figure 5). Because it was not possible to maintain the sterile conditions in the circulating water during 45 days, as a reference, the abiotic evaluation was performed in static conditions. As can be seen in Figure 5(a), 5(d), and 5(g), after exposure to the sterile water, all the metals showed low generalized corrosion. On the contrary, when bacteria were present, localized attack can be detected (Figure 5(b), 5(c), 5(e), 5(f), 5(h), and 5(i)). The distribution of the damage is in relation to the presence of the developed biofilm. However, due to the complexity of the real systems, it is not easy to correlate directly the final aspect of the exposed samples with only the biological film (Rosales et al. 2008), because also the surface original conditions, the geometric irregularities, and the hydrodynamic 
Biofilm aspect in water without As

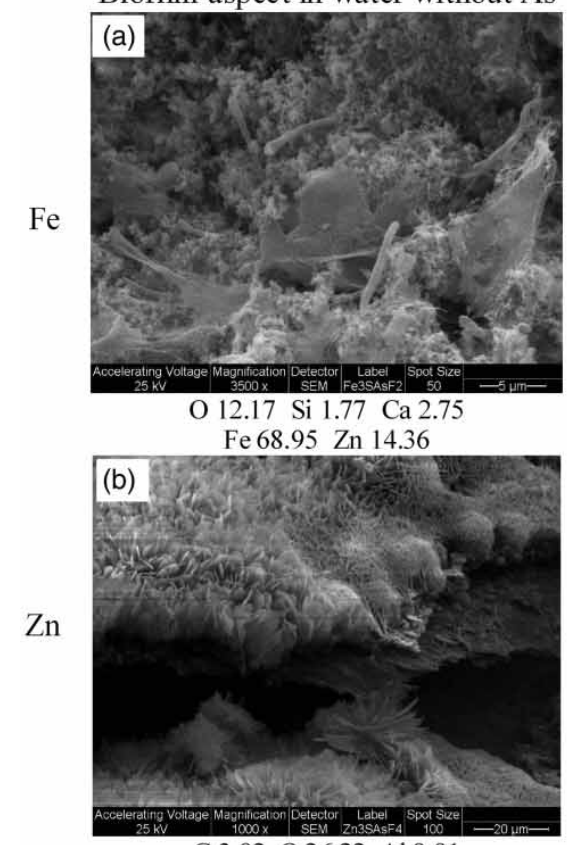

C 3.92 O $26.22 \mathrm{Al} 9.91$ $\mathrm{Si} 4.58$ Ca $1.89 \mathrm{Zn} 53.46$

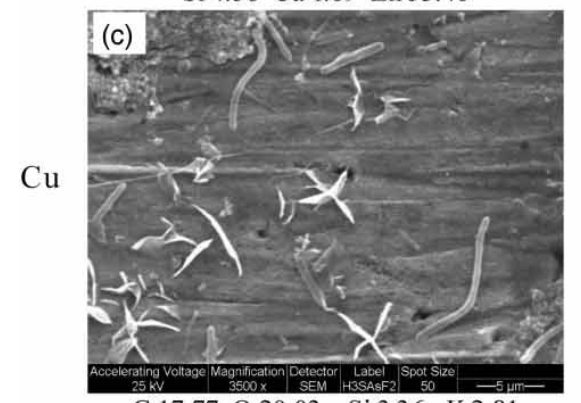

C 17.77 O 20.03 Si 3.36 K 2.81 $\begin{array}{lll}\text { Fe } 8.78 \quad \mathrm{Cu} 45.29 & \mathrm{Zn} 1.97\end{array}$

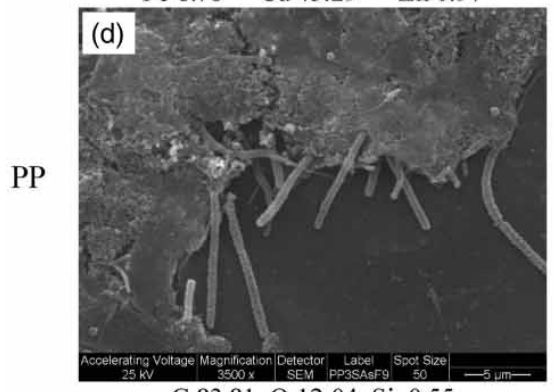

C 83.81 O 12.04 Si 0.55 $\mathrm{K} 0.30 \mathrm{Fe} 1.94 \mathrm{Cu} 1.37$
Biofilm aspect in water with As

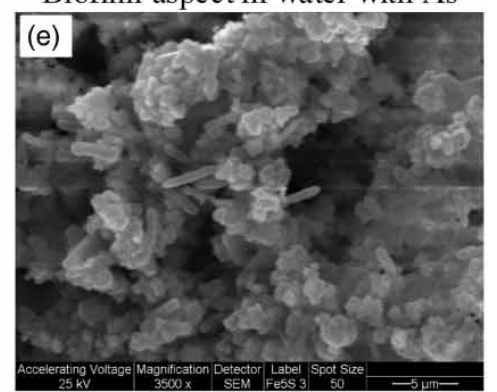

C 5.01 O $31.36 \mathrm{Mg} \mathrm{5.09} \mathrm{Si} 5.95$

Ca 3.55 Fe 33.72 Zn 11.17 As 4.15

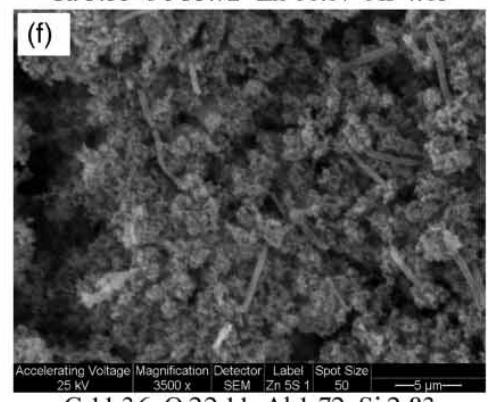

C 11.36 O 22.11 Al 1.72 Si 2.83

Fe $10.25 \mathrm{Cu} 1.11 \mathrm{Zn} 37.34$ As 13.27

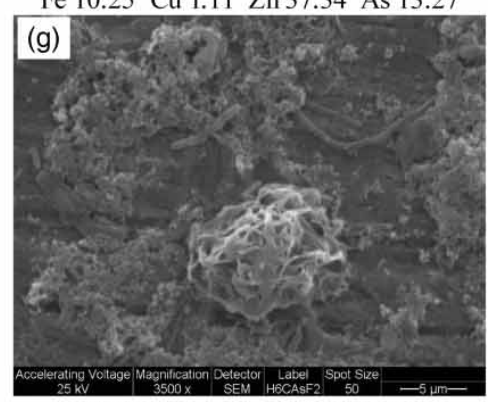

C 5.06 O 12.85 Si 1.26 K 0.27

Ca 0.53 Fe 2.23 Cu 75.12 As 2.68

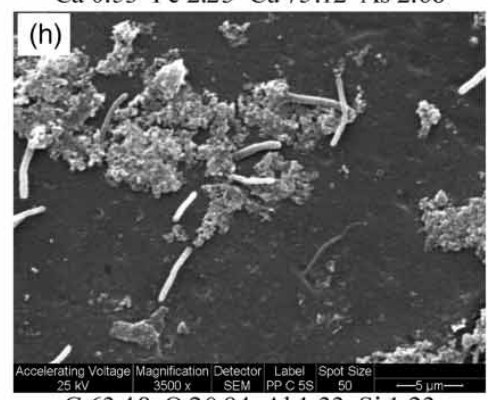

C 63.48 O 20.94 Al 1.33 Si 1.23

Fe $3.76 \mathrm{Cu} 2.78 \mathrm{Zn} 4.36$ As 2.11

Figure 4 | ESEM micrographs of the biofilms developed on the tested materials in both circuits: without As(V) (left column) and with As(V) (right column) (EDS values: \% w/W). Scale bars: (a) and (c)-(h) bar $=5 \mu \mathrm{m}(3,500 \times)$; (b) $=20 \mu \mathrm{m}(1,000 \times)$.

conditions would affect the real corrosion behavior underneath. The results obtained in the considered experimental arrangement are in good agreement with those observed in real distribution systems (Rosales 2007), which showed remarkable irregularities associated with uneven biofilm growth and soft underneath corrosion. 

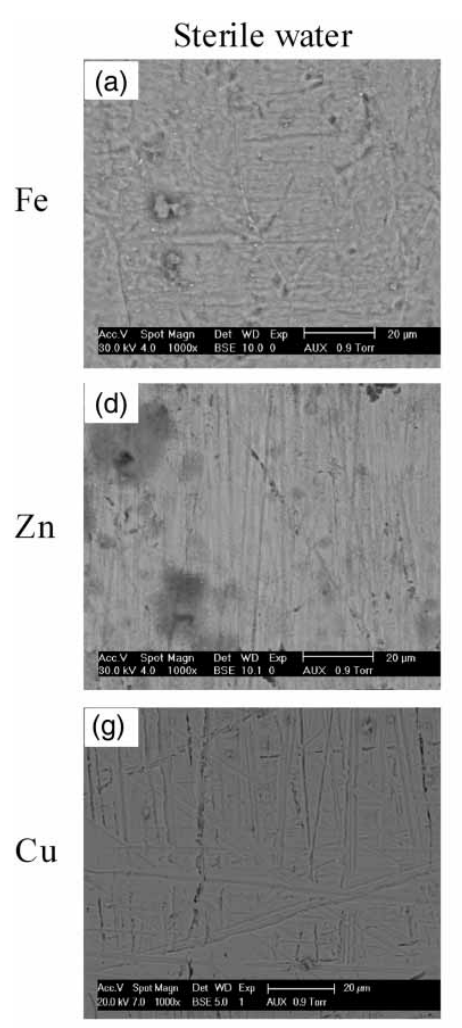
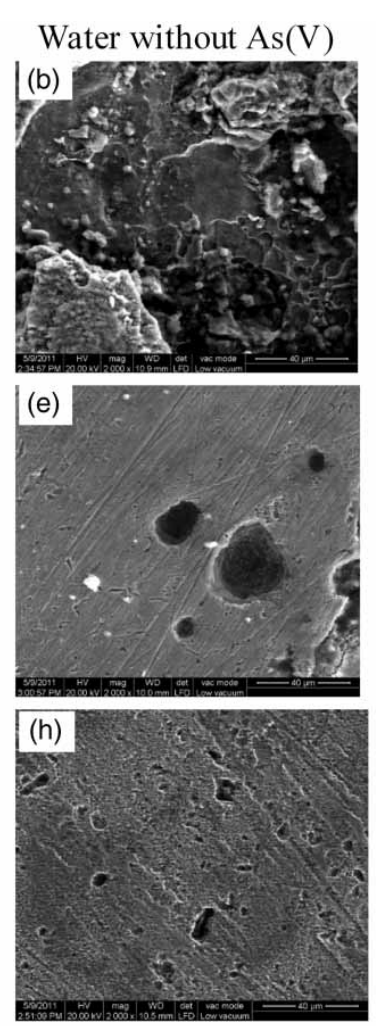
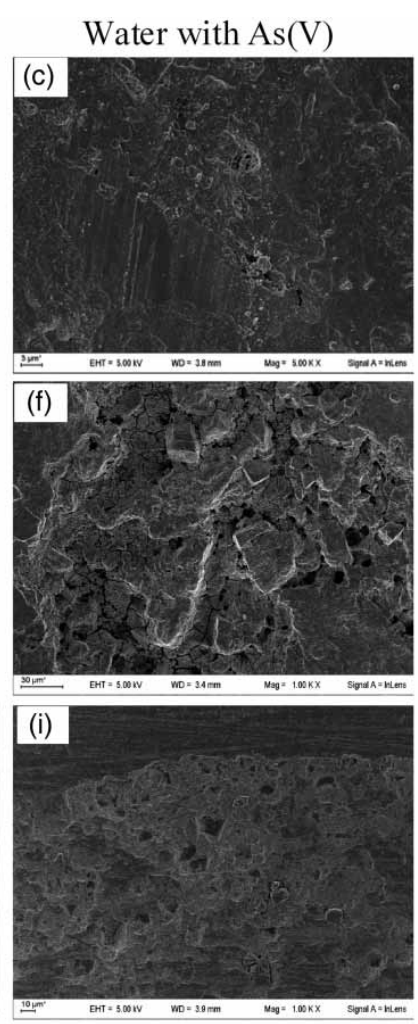

Figure 5 | SEM micrographs showing the aspect of corroded surfaces of the tested materials once deposits were removed. Scale bars: (a), (d), and (g) $20 \mu \mathrm{m}$ (1,000x); (b), (e), and (h) $40 \mu \mathrm{m}$ $(2,000 \times)$; (c) $3 \mu \mathrm{m}(5,000 \times)$; (f) $30 \mu \mathrm{m}(1,000 \times)$; (i) $10 \mu \mathrm{m}(1,000 \times)$.

Although SEM has a higher resolution for visualizing microbial biofilms than other imaging techniques, its requirements for the observation of biological samples may introduce artifacts (Priester et al. 2007). The analysis of undisturbed biofilms would provide much more information. CSLM might be used for that purpose providing three-dimensional simultaneous information on the inner and outer structure, composition, and compactness of biofilms (Neu et al. 2010). Using CSLM, images of the biofilms were taken on randomly selected sites every $5 \mu \mathrm{m}$ along the biofilm thickness; as an example the results obtained for $\mathrm{Zn}$ are shown in Figure 6. Those images
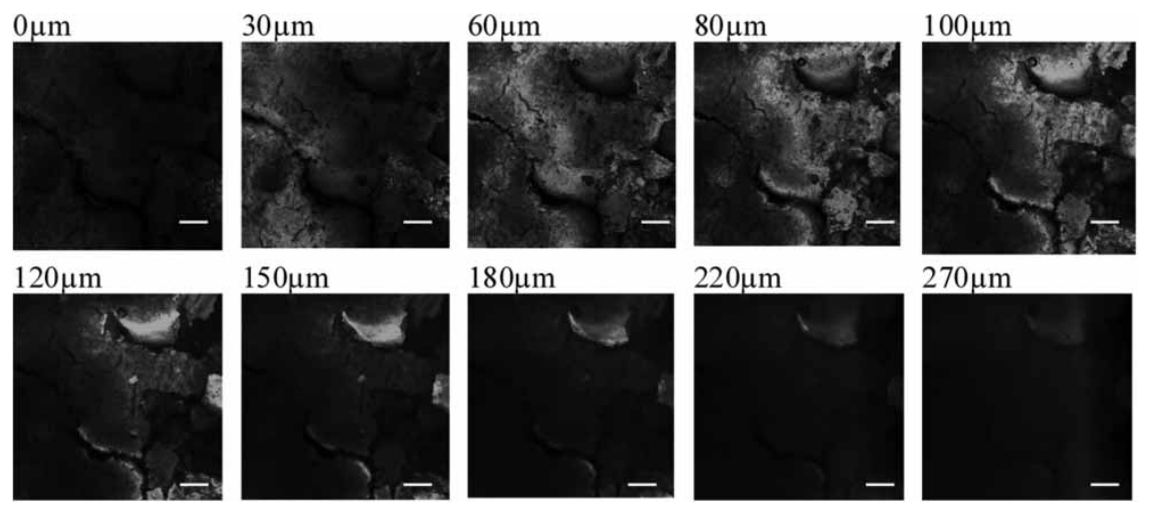

Figure 6 | CSLM images taken at different depths (from the outer surface of the biofilm at $0 \mu \mathrm{m}$ to the bottom (on the metallic surface) at $270 \mu \mathrm{m}$ ) of a biofilm formed on Zn. Scale bar: 200 $\mu \mathrm{m}$. 
revealed the internal structure of the biofilms formed on all the materials, showing a very heterogeneous topography, different cell spatial distribution, voids and channels in accordance with observations made using the same technique (Lewandowski \& Beyenal 2003).

Images obtained with the CSLM were processed using the software Image $\mathrm{J}$ and the percentage of the overall biofilm coverage was estimated (Table 3). Except for $\mathrm{Cu}$, the surface coverage resulted significantly higher on those coupons exposed to the As-containing water; these results confirmed the appreciation made by naked eye. The observed influence of toxic compounds in the development of the sessile form of life over the planktonic form was also reported by other authors (Fang et al. 2002). From the observation of 3D images reconstructed from CSLM photographs, the distribution and local thickness of the coating could be estimated (Figure 7). The brightness and density of the white points in the cross-section view are related to the compactness and thickness of the biofilms. In accordance with the ESEM observations, the cross-sections corresponding to $\mathrm{Cu}$ and $\mathrm{PP}$ revealed the formation of thin and discontinuous biofilms, while in the case of $\mathrm{Fe}$ and $\mathrm{Zn}$, biofilms were thicker and continuous.

\section{Electrochemical anodic polarization}

To evaluate the influence of the complex film (biological material + corrosion products + spurious solids) on the electrochemical response of the metallic substrata, anodic polarization curves were performed. Non-exposed, ground coupons were used as blanks. The obtained results are shown in Figure 8. As it was expected taking into account the electrochemical reactivity of the considered substrata,

Table 3 | Percentage of substratum covered by biofilm in presence and absence of arsenic in the circulating water

\begin{tabular}{lll} 
& \multicolumn{2}{l}{ Coverage (\%) } \\
\cline { 2 - 3 } Substratum & Without As & With As \\
\hline $\mathrm{Fe}$ & 12.83 & 41.16 \\
$\mathrm{Zn}$ & 30.34 & 35.28 \\
$\mathrm{Cu}$ & 17.59 & 18.21 \\
$\mathrm{PP}$ & 5.27 & 27.18 \\
\hline
\end{tabular}

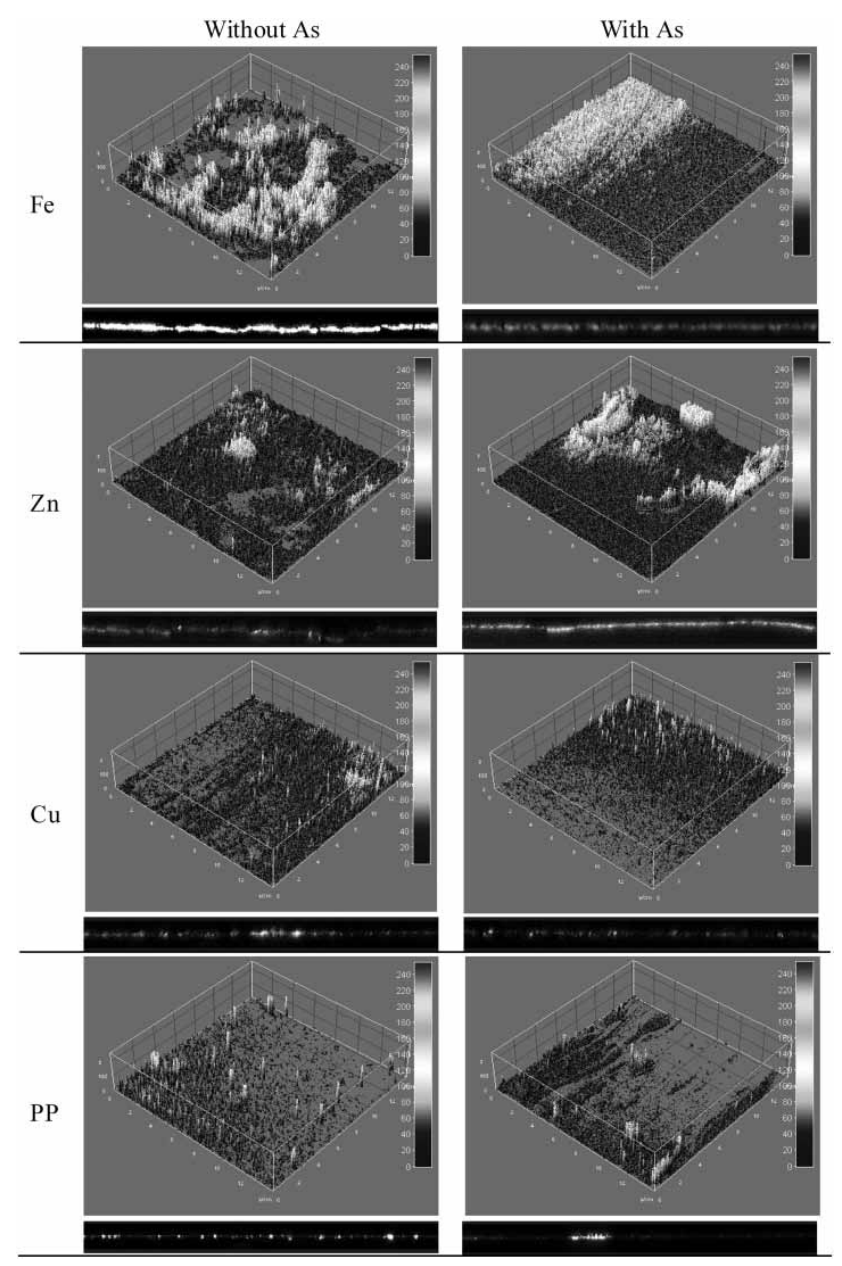

Figure 7 | 3D structure of biofilm formed on all materials after exposure to both circuits; surface scanned: $1.4 \mathrm{~mm} \times 1.4 \mathrm{~mm}$. Bottom image: cross-section view of the 3D images.

$\mathrm{Zn}$ presented the most negative corrosion potential $\left(E_{\text {corr }}\right) \approx-1.4 \mathrm{~V}$ (SSE), followed by $\mathrm{Fe} \approx-0.9 \mathrm{~V}$ (SSE), and $\mathrm{Cu} \approx-0.4 \mathrm{~V}$ (SSE). All the ground materials showed active dissolution with a well-defined blockage effect due to anodic products accumulation on the surface as the polarization level increased. The potential at which this behavior began was directly dependent on the amount and morphology of the formed products.

In the presence of the complex film, in general, no significant effect on the $E_{\text {corr }}$ values was observed. The only exception was the case of Fe samples previously exposed to the As-containing water, for which a positive shift of $\approx 40 \mathrm{mV}$ was observed. This behavior would be related to an increase of the barrier effect afforded by the complex 


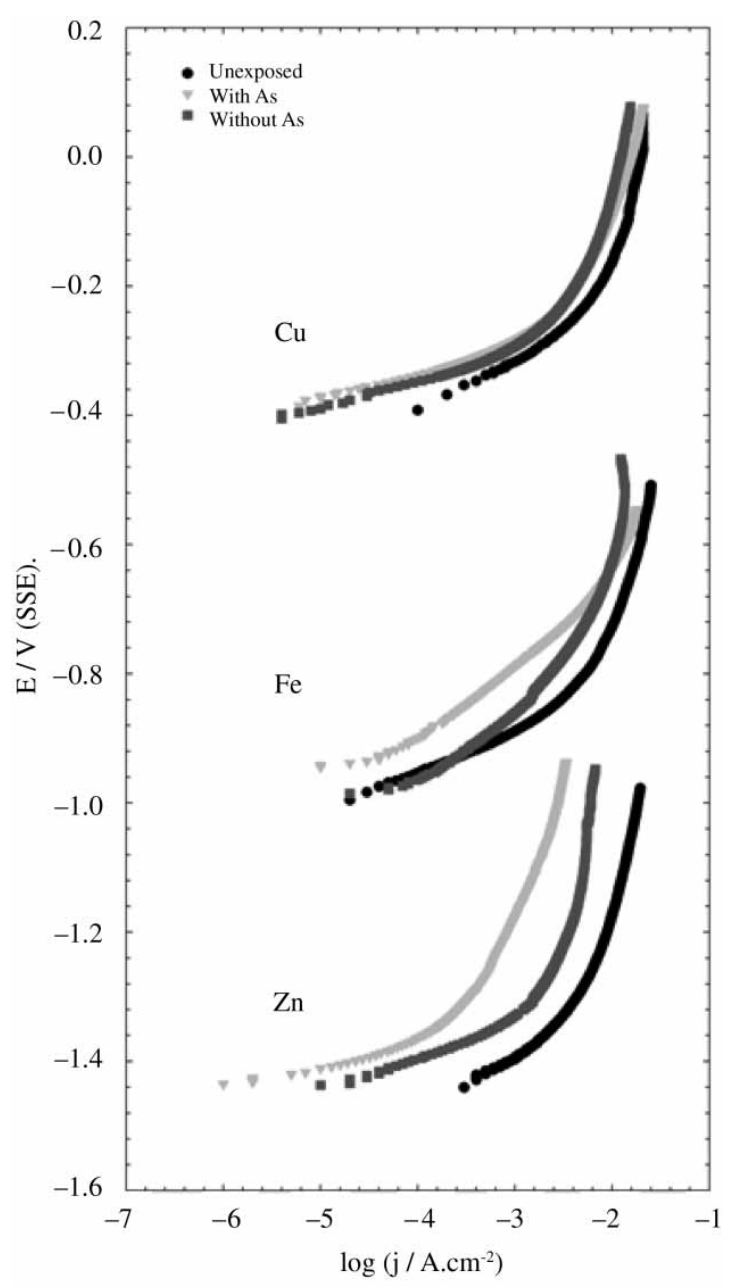

Figure 8 | Anodic polarization curves of the metallic tested materials before and after exposure to circulating water.

film due to the particular influence of the presence of $A s(V)$ on the microbial community and on the development of the corrosion process of the substratum. On the contrary, the grown films produced a displacement of the anodic curves to lower current densities. This effect was more significant for $\mathrm{Zn}$ than for $\mathrm{Fe}$ and almost irrelevant for $\mathrm{Cu}$. The blockage effect due to the presence of the complex film was higher for samples exposed to drinking water in the presence of $\mathrm{As}(\mathrm{V})$. This behavior is in good agreement not only with the biofilm amount, structure, and morphology shown in Figures 4 and 7 but also with the electrochemical reactivity and morphology of the corrosion products of the considered materials. As was mentioned earlier, the presence of $\mathrm{As}(\mathrm{V})$ generated, in general, an increase in the heterotrophic sessile bacteria counts as well as in the amount of the EPS with the consequent increase on the thickness and compactness of the biofilm. In addition, the amount of corrosion products formed on $\mathrm{Zn}$ was higher than on $\mathrm{Fe}$ and, as their compactness was greater too, the barrier effect afforded by the complex film built up on $\mathrm{Zn}$ along exposure resulted in being higher. As a consequence of that, the observed decrease of the anodic current was more important (Figure 8). The worthless barrier effect observed for $\mathrm{Cu}$ samples was related to the low biofilm development on its surface in both circuits.

\section{CONCLUSIONS}

The presence of $A s(V)$ in the circulating water showed a significant influence on the development of the biofilms on the exposed materials. The $\mathrm{As}(\mathrm{V})$ addition modified not only the morphology but also the surface coverage afforded by the biofilms on $\mathrm{Zn}, \mathrm{Fe}$, and PP. This behavior was not observed on $\mathrm{Cu}$, possibly due to the biocidal synergism of $\mathrm{Cu}^{2+}$ and $\operatorname{As}(\mathrm{V})$.

The presence of $\mathrm{As}(\mathrm{III})$ as claudetite $\left(\mathrm{As}_{2} \mathrm{O}_{3}\right)$ on PP coupons, reveals the capability of any bacterial species to use $\mathrm{As}(\mathrm{V})$ as an electron acceptor during anaerobic respiration.

The presence of the biofilm had a relevant effect on the corrosion behavior of the metallic substrata during exposure, developing localized corrosion.

The anodic polarization curves provided evidence that the highest barrier effect was afforded by the complex film developed on $\mathrm{Zn}$, particularly in the water circuit with $\operatorname{As}(\mathrm{V})$. This is due not only to the thicker and more compact biofilm but also to the volume and compactness of the formed corrosion products.

\section{ACKNOWLEDGMENTS}

Financial support for this work from the governmental Agencia Nacional de Promoción Científico-Tecnológica, PICT 38380, is gratefully acknowledged. The cold rolling work of all the metal samples was performed by Dr E. G. Maffía at Facultad de Ingeniería of the UNLP, La Plata, Argentina. 


\section{REFERENCES}

ASTM G1-03 20I Standard Practice for Preparing, Cleaning, and Evaluating Corrosion Test Specimens. ASTM International, West Conshohocken, PA.

Beech, I. B. \& Sunner, J. 2004 Biocorrosion: towards understanding interactions between biofilms and metals. Curr. Opin. Biotech. 15 (3), 181-186.

Beech, I. B., Sunner, J. A. \& Hiraoka, K. 2005 Microbe-surface interactions in biofouling and biocorrosion processes. Int. Microbiol. 8 (3), 157-168.

Branda, S. S., Vik, A., Friedman, L. \& Kolter, R. 2005 Biofilms: the matrix revisited. Trends Microbiol. 13 (1), 20-25.

Chatterjee, A., Das, D., Mandal, B. K., Chowdhury, T. R., Samanta, G. \& Chakraborty, D. 1995 Arsenic in groundwater in six districts of West Bengal, India: the biggest arsenic calamity in the world. Part 1 . Arsenic species in drinking water and urine of the affected people. Analyst 120 (3), 643-656.

Das, D., Chatterjee, A., Mandal, B. K., Samanta, G., Chakroborty, D. \& Chanda, B. 1995 Arsenic in groundwater in six districts of West Bengal, India: the biggest arsenic calamity in the world. Part 2. Arsenic concentration in drinking water, hair, nails, urine, skin-scales and liver tissues (biopsy) of the affected people. Analyst 120 (3), 917-924.

Fang, H., Xu, L.-C. \& Chan, K.-Y. 2002 Effects of toxic metals and chemicals on biofilm and biocorrosion. Water Res. 36 (19), 4709-4716.

Farías, S., Casa, V., Vázquez, C., Ferpozzi, L., Pucci, G. \& Cohen, I. 2003 Natural contamination with arsenic and other trace elements in ground waters of Argentine Pampean Plain. Sci. Total Environ. 309 (1-3), 187-199.

Frost, F., Frank, D., Pierson, K., Woodru, L., Raasina, B., Davis, R. \& Davies, J. 1993 A seasonal study of arsenic in groundwater, Snohomish County, Washington, USA. Environ. Geochem. Health 15 (4), 209-214.

Lehtola, M. J., Laxander, M., Miettinen, I. T., Hirvonen, A., Vartiainen, T. \& Martikainen, P. J. 2006 The effects of changing water flow velocity on the formation of biofilms and water quality in pilot distribution system consisting of copper or polyethylene pipes. Water Res. 40 (11), 2151-2160.

Lewandowski, Z. \& Beyenal, H. 2003 Biofilm monitoring: a perfect solution in search of a problem. Water Sci. Technol. 47 (5), 9-18.

Masud Karim, M. D. 2000 Arsenic in groundwater and health problems in Bangladesh. Water Res. 34 (1), 304-310.

Neu, T. R., Manz, B., Volke, F., Dynes, J. J., Hitchcock, A. P. \& Lawrence, J. R. 2010 Advanced imaging techniques for assessment of structure, composition and function in biofilm systems. FEMS Microbiol. Ecol. 72 (1), 1-21.

Nicolli, H., Bundschuh, J., Blanco, M., Tujchneider, O., Panarello, H., Dapeña, C. \& Rusansky, J. 2012 Arsenic and associated trace-elements in groundwater from the Chaco-Pampean plain, Argentina: results from 100 years of research. Sci. Total Environ. 429, 36-56.

Ollos, P. J., Huck, P. M. \& Slawson, R. M. 2003 Factors affecting biofilm accumulation in model distribution systems. J. Am. Water Works Assoc. 95 (1), 87-97.

Oremland, R. S. \& Stolz, J. F. 2005 Arsenic, microbes, and contaminated aquifers. Trends Microbiol. 13 (2), 45-49.

Oremland, R. S., Stolz, J. F. \& Hollibaugh, J. T. 2004 The microbial arsenic cycle in Mono Lake, California. FEMS Microbiol. Ecol. 48 (1), 15-27.

Pérez-Carrera, A. \& Fernández-Cirelli, A. 2007 Arsenic in the southeast plains of Córdoba province, Argentina. Biotransference to bovine milk. Vet. Res. 9 (1), 123-135.

Pitts, B. \& Stewart, P. 2008 Confocal laser microscopy on biofilm: successes and limitations. Microsc. Today 16 (4), $18-22$.

Pontius, F. W., Brown, K. G. \& Chen, C. J. 1994 Health implications of arsenic in drinking water. J. Am. Water Works Assoc. 86 (9), 52-63.

Priester, J. H., Horst, A. M., Van De Werfhorst, L. C., Saleta, J. L., Mertes, L. A. K. \& Holden, P. A. 2007 Enhanced visualization of microbial biofilms by staining and environmental scanning electron microscopy. J. Microbiol. Methods 68 (3), 577-587.

Rosales, B. 2007 Residual useful life estimate of the Buenos Aires drinking water network. In: Environmental Change and Rational Water Use (O. E. Scarpati \& J. A. A. Jones, eds), International Geographical Union (UGI). Orientación Gráfica Editora, Buenos Aires, pp. 410-417.

Rosales, B., Pujol, M. \& Rastelli, E. 2008 Initial steps on microbial colonization and corrosion on drinking water networks. 17th ICC, NACE, Las Vegas, NE, USA, Paper \# 2519.

Walker, J. T., Verran, J., Boyd, R. D. \& Percival, S. 200I Microscopy methods to investigate structure of potable water biofilms. Methods Enzymol. 337, 243-255.

Wang, H., Hu, X. \& Hu, C. 2012 Effect of chlorine and pipe material on biofilm development and structure in a reclaimed water distribution system. Water Sci. Technol. Water Supply 12 (3), 362-371.

Yu, J., Kim, D. \& Lee, T. 20Iо Microbial diversity in biofilms on water distribution pipes of different materials. Water Sci. Technol. 61 (1), 163-171. 